\title{
Creating a Shared Neuroscience Collection Development Policy
}

\author{
ELIZABETH KETTERMAN \\ JEANNE HOOVER \\ KATHY CABLE \\ East Carolina University, Greenville, North Carolina, USA
}

At East Carolina University, Joyner Academic and Laupus Health Sciences Libraries collaborated on a shared Neuroscience collection development policy, primarily as a reaction to state-level budget cuts. The policy aims to limit duplication in purchases at each library location, but also describes the materials that are most appropriate for selection by each library and explores the usefulness of e-book purchases as a cost-saving measure. The result of this collaborative effort is a comprehensive neuroscience collection for the University's libraries.

KEYWORDS collection development policy, neuroscience, e-books, collaboration

\section{INTRODUCTION}

Neuroscience is an emerging health sciences field that incorporates a wide range of subjects from psychology to neurobiology. This interdisciplinary field is described as, "'one of the last frontiers in the biological sciences' by neuroscientist and Nobel Prize recipient, Dr. Eric Kandel". ${ }^{1}$

At East Carolina University (ECU), the Neuroscience program spans departments on both the academic and health sciences campuses therefore both Joyner Academic Library Services 
and the Laupus Health Sciences Library collect materials in the subject area. This crosscollecting process worked well for the libraries until budget cuts in recent years forced the libraries to reduce spending. Subject areas collected for by both libraries were scrutinized and the librarians collecting for the neuroscience disciplines decided to create a shared collection development policy as a guide to avoid duplication in purchases and thus reduce spending.

In the process of creating this policy, we discovered the value of the e-book as a way to reduce duplicate purchases as well as the value in collaborating with our librarian colleagues and the neuroscience faculty whom we consulted during the policy development process. This paper discusses the process by which the policy was written, the policy itself, and the positive outcomes of the relationships built in order to develop an unduplicated, comprehensive neuroscience collection.

\section{LITERATURE SCAN AND BACKGROUND}

Collaboration between librarians has been an essential aspect of the profession for years. With the increased need for libraries to embrace new technologies while at the same time facing budget constraints, collaboration has now become a necessity. Many states have formed their own consortia, such as OhioLINK, in order to share resources. ${ }^{2}$ By leveraging their buying power, libraries are able to increase their resources while also retaining their research niche. ${ }^{2}$ The impacts of these kinds of consortia have caused some libraries to reconsider their collection development policies. In a recent article on revising collection development policies, Douglas noted the importance for their policy to reflect the current and future states of collection development and be flexible enough to adjust to these changes. ${ }^{3}$ 
ECU faces these same problems. The University hosts three physical libraries: Joyner Library (Academic), the Music Library, and Laupus Library (Health Sciences). Joyner Library and the Music Library are located on the main campus while Laupus Library is located on the Medical Campus, a few miles across the city of Greenville, North Carolina. Even though the libraries appear to be a single entity, Laupus Library's funding is separate from Joyner Library and the Music Library. Furthermore, while we collaborate to share electronic resources, our book budgets are completely separate.

During the fall of 2010, the Science Librarian (Academic), Library Liaison for the School of Medicine (Health Sciences), and the Collection Development Librarian (Health Sciences) met to discuss the research and resource overlaps for the neuroscience collection. We realized that our dependence upon quick searches of the library catalog was not working as a measure against duplication of purchases. We needed to create a shared policy that would delineate by call number range which library should buy particular titles.

We also decided that this policy should address the need for and usefulness of e-book purchases for this subject area. The considerations for this emphasis on ebook purchases is summed up in a study at Duke University which found that e-books circulated at higher numbers because, "more than one user can access the title during a traditional circulation period and because e-books are often used for ready reference" ${ }^{4}$

\section{METHODS}

First, we identified the programs in the interdisciplinary area of neuroscience that fell under our libraries' responsibilities. At ECU, that includes undergraduates in the 
Multidisciplinary Studies Program. Many of the course requirements in the curriculum overlap with the undergraduate courses required by most medical schools (e.g., biology, chemistry, physics). The curriculum includes a strong core of required biology, chemistry, physics, and psychology courses which are primarily purchased by Joyner library for these undergraduate students. The graduate students are scattered among different departments including Anatomy, Physiology, Pharmacology, Microbiology, Communicative Sciences and Disorders, and Human Performance. The graduate-level information these students need are primarily purchased by Laupus library.

In the next step we analyzed different collection development policies for interdisciplinary studies with a focus on neuroscience-related policies. The most readily available neuroscience collection development policy was at Oberlin College Library in Oberlin, Ohio. ${ }^{5}$ This policy was used as a model for developing an interdisciplinary collection for neuroscience. We also reviewed current ECU collection policies to reflect standard institutional collecting.

At this point, liaisons at both libraries spoke with faculty and students about their research needs at their respective campuses. As Tucker, Bullian, and Torrence state, "Collaborating with academic departments is a mutually beneficial process. First, it helps librarians with their job of . . selecting resources for the collection." ${ }^{6}$ We found that these conversations uncovered information needs that scanning websites and departmental pages cannot reflect alone. Collaboration with faculty colleagues in the neuroscience departments was invaluable. 
We reviewed possible call number overlaps in Library of Congress and the National Library of Medicine Classification systems. We then consulted with the psychology liaison to identify others since, typically, neuroscience texts that are cataloged in that call number range are ordered by the psychology liaison. Interlibrary loan requests for neuroscience resources were also reviewed to identify any areas that might be lacking in our local collections.

\section{RESULTS}

In order for each library to focus on the subject areas relevant to their patron base, the librarians analyzed the Library of Congress (Table 1.) and National Library of Medicine (Table 2.) classification schedules. Primary headings for each schedule were identified. Since neuroscience is an interdisciplinary field, some titles cataloged in broader disciplines like Biology and Brain Diseases were relevant; therefore, secondary headings and ranges were also identified for each schedule. Titles falling in the secondary tier would be given more scrutiny by a librarian selector than those in the primary tier.

Table 1. LC call number ranges

Table 2. NLM call number ranges

Electronic purchases reduce duplication in the collection, so electronic was deemed preferable to print. Electronic materials are also important for this subject area since the Neuroscience program at ECU depends heavily on current and new research and electronic materials are updated in ways unmatched by print materials. Electronic also insures that neuroscience faculty and students will have equitable access to the materials, which benefits distance 
education students who are studying from afar. Additionally, patrons on either campus who do not have easy access to the print materials at the opposite library will also benefit.

We decided that specific materials and optimal formats should also be defined. The following formats were identified as being appropriate for the neuroscience collection:

- Monographs (Books): The collection will include print and electronic books. Electronic books are preferred whenever available.

- Journals and Electronic Resources: Journals will be added in electronic format unless unavailable in this format.

- Reference Materials: This includes encyclopedias, handbooks, indexes, dictionaries, and other specialized reference materials.

- Videos and DVDs: These materials will be added to the collection by faculty request and/or selector choice.

- Theses and Dissertations: All theses and dissertations completed by East Carolina University students will be added to the Institutional Repository, the Scholarship.

- Government Documents: These materials may be acquired in consultation of the Government Documents Librarian.

We also determined that federal or other government agencies producing quality information beneficial for neuroscience research would be worth listing in the policy. These agencies' websites are reviewed as potential sources of collection materials:

- Health and Human Services Development

- U.S. Department of Education 


\section{- Environmental Protection Agency}

- Congressional Reports \& Documents - Office of Technology Assessment

- Library of Congress

\section{- US Department of Defense}

As mentioned earlier, each library manages its own approval plan and works with a separate approval plan vendor. This could have been a glitch in our efforts to reduce duplication with e-book purchases. If each library uses a unique book vendor, how will those vendors know which books the other library has purchased? Luckily, the book vendors, Matthews Medical Bookseller and Yankee Book Peddler, both use a common e-book provider by ProQuest - ebrary. Ebrary's knowledgebase allows the bookseller to know when a title has been purchased by either library since ebrary considers East Carolina University a single library system (we even share the ebrary license agreement). This shared e-book provider is a key to eliminating duplication in e-book purchases.

In addition to the approval plans, each library also uses the following tools to make decisions for neuroscience purchases:

- Book review sources

- Requests by faculty and/or students

- Publishers' catalogs

- Recommended titles from professional societies such as The Society for Neuroscience 
- Recommended titles from sources such as The Best Books for University Libraries, Resources for College Libraries, Medical Library Association News, and others.

A complete copy of the ECU Neuroscience Collection Development Policy can be found here: http://www.ecu.edu/laupuslibrary/about/Policies.cfm.

\section{DISCUSSION AND FUTURE PLANS}

Now that the policy is in place, the librarians have determined future plans for evaluation. We will evaluate circulation statistics to determine total utilization of our selections. Currently, we do have some preliminary usage statistics for our ebrary selections. In the neurosciences call number ranges, we can observe that in the past year there have been 157 sessions in 44 purchased titles. We cannot tell how many purchased titles have a zero usage count which is a limitation of the ebrary admin module. The average ebrary circulation per title is 3.57 , while print circulation in similar call number ranges is 3.17 . We believe this is good usage since the ebrary titles have been available for approximately one year and our print collection spans multiple decades worth of purchases. These statistics seems to indicate that e-book titles will be more highly circulated over time than our print titles in the same subject area.

Another plan is to communicate with faculty to determine satisfaction with the collection. Since their anecdotal input was so valuable when we began the initial policy creation research, we believe it will be just as valuable to go back to the faculty and ask if they have observed an improvement in the collection over time. 
ECU is accredited by the Southern Association of Colleges and Schools (SACS). A component of their accreditation standards addresses learning resources and services; specifically, the suggested documentation supporting this standard includes policies and procedures governing collections and access to other library/learning resources. We expect that the neuroscience collection development policy will be a vital supporting document for this SACS accreditation process, to be completed in 2013.

We will also assess the actual cost savings achieved by following the policy. We will compare the costs of the ebrary titles purchased for the neurosciences against what duplicate copies of print books would have cost the libraries before the purchasing guidelines were implemented.

\section{CONCLUSION}

In creating a shared neuroscience collection development policy, librarians at East Carolina University's academic and health sciences libraries have taken steps to reduce spending. Electronic books allow the librarians reduce duplication since the license agreements for these titles span across the entire campus, and also expose the literature to more people in a more convenient manner. A secondary outcome of this collaborative process is the relationship building between the librarians themselves and the faculty and students they serve. These relationships are difficult to quantify, but are so vital to creating quality collections. We can better understand the needs of our users by simply asking them what research they conduct and what materials they need to support that research or curriculum. This, in turn, gives us a better understanding of our own collections. 


\section{REFERENCES}

1. East Carolina University. "Neuroscience Home." Available from http://www.ecu.edu/cscas/neuro/. Accessed: March 16, 2012.

2. Kinner, Laura, and Alice Crosetto. "Balancing Act for the Future: How the Academic Library Engages in Collection Development at the Local and Consortial Levels." Journal of Library Administration 49, no. 4 (2009): 419-437.

3. Douglas, C. Steven. "Revising a Collection Development Policy in a Rapidly Changing Environment " Journal of Electronic Resources in Medical Libraries 8, no. 1 (2011): 15 21.

4. Grigg, Karen S., Bethany A. Koestner, Richard A. Peterson, and Patricia L. Thibodeau. "Data-Driven Collection Management: Through Crisis Emerge Opportunities " Journal of Electronic Resources in Medical Libraries 7, no. 1 (2010): 1 - 12.

5. Oberlin College Library. "Oberlin College Library Collection Development Policy Subject Statement: Neuroscience and Biopyschology." Available from http://www.oberlin.edu/library/collectiondev/subjects.html. Accessed: March 7, 2012.

6. Tucker, James Cory, Jeremy Bullian, and Matthew C. Torrence. "Collaborate Or Die! Collection Development in Today's Academic Library " The Reference Librarian 40, no. 83-84 (2004): 219-236. 